\title{
Effect of Deposition Temperature on Some Properties of MOCVD Molybdenum Sulphide Thin Films
}

\author{
Bolutife Olofinjana ${ }^{1}$, Gabriel Osaze Egharevba ${ }^{2}$, Bidini Alade Taleatu ${ }^{1}$, Olumide Oluwole Akinwunmi ${ }^{1}$ and \\ Ezekiel Oladele Bolarinwa Ajayi ${ }^{1}$ \\ 1. Department of Physics, Obafemi Awolowo University, Ile-Ife, Nigeria \\ 2. Department of Chemistry, Obafemi Awolowo University, Ile-Ife, Nigeria
}

Received: April 10, 2014 / Accepted: April 22, 2014 / Published: April 25, 2014.

\begin{abstract}
Molybdenum sulphide thin films were deposited on sodalime glass, silicon wafer and stainless steel (AISI 304L) substrates using Metal Organic Chemical Vapour Deposition (MOCVD) technique at temperatures ranging from $360{ }^{\circ} \mathrm{C}$ to $450{ }^{\circ} \mathrm{C}$. The films were characterized using Rutherford Backscattering Spectroscopy (RBS), Ultraviolet-Visible Spectroscopy, Four point probe technique, Scanning Electron Microscopy (SEM) and Atomic Force Microscopy (AFM). Elemental analysis showed that the S/Mo ratio increases from 1.22 to 2.33 with increasing temperature. The optical band gap varies from $1.69 \mathrm{eV}$ to $1.79 \mathrm{eV}$ as deposition temperature increases. The electrical conductivity ranging from $0.5 \Omega^{-1} \mathrm{~cm}^{-1}$ to $1.30 \Omega^{-1} \mathrm{~cm}^{-1}$ also depends on deposition temperature. SEM micrographs of the films showed the layered structure of the film with an estimated grain size that increases from $1.6 \mu \mathrm{m}$ to $2.4 \mu \mathrm{m}$ as the deposition temperature increases. This study demonstrates that the properties of the films depend on the deposition temperature.
\end{abstract}

Key words: Substrate, temperature, thickness, band gap, morphology.

\section{Introduction}

Molybdenum sulphide is a technologically important transition metal chalcogenide material which has drawn considerable attention as functional materials for many important applications such as solar cells [1, 2], photovoltaic cells $[3,4]$, field emitters $[5,6]$, thermoelectric materials [7], catalyst in electrochromic devices [8], and so on. It also exhibits a strong degree of anisotropy in their properties. All these properties are closely related to the microstructure of the material which in turn depends on the different preparation techniques as well as the process conditions that are associated with these techniques.

Despite all the promising characteristics of molybdenum sulphide, its use in optoelectronic devices is held back by difficulty in preparing thin films of this compound with desired properties useful in

Corresponding author: Bolutife Olofinjana, Ph.D., research field: material physics. E-mail: olofinb@oauife.edu.ng. optoelectronics. As a result, many scientific and technological problems have to be solved before molybdenum sulphide thin films could be widely used in optoelectronic devices fabrications.

Deposition technology can be regarded as one of the major key factors in optoelectronic device fabrication. Since these devices require very high purity thin films with precise control of uniformity, composition, structure, morphology and ultimately properties; the process conditions associated with the various deposition techniques need to be manipulated in such a way so as to give the desired properties.

A wide range of techniques had been used to prepare molybdenum sulphide. Some of these techniques are purely physical such as sputtering $[3,9,10]$, or purely chemical such as chemical vapor deposition (CVD) [11-13], while considerable number combines both physical and chemical reactions [14]. However, to achieve good optical performance as well as high 
stability lasting a long time, there is need for low cost preparation technique capable of producing molybdenum sulphide thin films with required microstructure and ultimately properties.

Metal Organic Chemical Vapor Deposition (MOCVD) has become one of the most important technique for preparing thin films and coatings of a large variety of materials essential to advanced technology where some of the most sophisticated conditions must be met. The main feature of MOCVD is its versatility in synthesizing both simple and complex components with relative ease sometimes at low temperature.

In MOCVD process, the choice of precursor; reaction chemistry and deposition conditions such as pressure, input concentration, gas flow rate, reactor geometry and operating principles, deposition temperature, among others, determines the microstructure and related properties of the film. The use of single solid precursors also simplifies the control of process parameters.

The growth of molybdenum sulphide from a single solid source precursor using MOCVD at deposition temperature of $420{ }^{\circ} \mathrm{C}$ has been previously demonstrated [15]. However, in this present study, the effect of deposition temperature (while other parameters are kept constant) on the stoichiometry, morphology, roughness as well as the electrical and optical properties of molybdenum sulphide thin films deposited by MOCVD technique using a single solid source precursor has been investigated.

\section{Experiments}

The precursor preparation and the deposition procedure have been reported earlier [15]. The substrates used are sodalime glass slides with composition $\mathrm{O}, \mathrm{Si}, \mathrm{Na}, \mathrm{Ca}, \mathrm{Mg}, \mathrm{Al}=60,25,10,3,1,1$, stainless steel sheet AISI304L and silicon wafer. The films were deposited at temperatures $360{ }^{\circ} \mathrm{C}, 380{ }^{\circ} \mathrm{C}$, $400{ }^{\circ} \mathrm{C}$ and $450{ }^{\circ} \mathrm{C}$. Before deposition, series of steps were taken for cleaning the substrate. They were washed gently in each of trichloroethylene, acetone, methanol and distilled water. The substrates were further inserted in a solution containing $15 \mathrm{~cm}^{3}$ of water, $6 \mathrm{ml}$ of $\mathrm{H}_{2} \mathrm{O}_{2}$ and $3 \mathrm{~cm}^{3}$ of $\mathrm{NH}_{4} \mathrm{OH}$ and heated at $75^{\circ} \mathrm{C}$ to $80^{\circ} \mathrm{C}$ for 5 to $10 \mathrm{~min}$. Lastly, the substrates were then rinsed several times with distilled water and were then left to dry.

Rutherford backscattering spectroscopy (RBS) was used to determine the stoichiometry and thickness of the films. The facility is a $7 \mathrm{MV}$ Tandem accelerator of IBM geometry (scattering configuration where the incident beam, surface normal, and detected beam are all coplanar) using $\mathrm{He}^{+}$of energy $2.2 \mathrm{MeV}$ and beam current $3.8 \mathrm{nA}$ with integrated beam dose of $10.0 \mu \mathrm{C}$ as the incident beam. The detector solid angle is 0.833 msr with a resolution of $12 \mathrm{KeV}$.

In order to study the optical behavior of the thin films with respect to deposition temperature, the optical absorbance of the thin films (deposited on sodalime glass) were investigated using Pye-Unicam 400 series Helios Alpha Version 2.05 UV-Visible spectrophotometer. All measurements were made at room temperature with blank sodalime glass substrate in the reference beam. Standardization was done by first replacing the coated substrate with a plain substrate in the sample position.

The electrical property of the films was investigated using the four point probe technique. The four point collinear probe configuration was employed with silver paste at each of the four points for ohmic contact. The deposited paste was cured at $50{ }^{\circ} \mathrm{C}$ for $24 \mathrm{~h}$ before the tests were carried out. Keithley 2400 Source meter with Rolls and Keener probes was used for the current-voltage measurement. The two outer probes were used to source current while the two inner probes sense the resulting voltage drop across the sample. The distance of separation between each of the probe was $1 \mathrm{~cm}$. A hand lens was used to monitor the probe so that it will not puncture the film.

The surface morphology were carried out using 
Zeiss Supra 40 with GEMINI column Scanning Electron Microscope with electron beam of 0.1 $\mathrm{keV}-30 \mathrm{keV}$ and nominal resolution of $1 \mathrm{~nm}$ at $10 \mathrm{keV}$. Surface roughness of the films was done using PSIA-XE 100 Atomic Force Microscopy machine. To achieve atomic scale resolution, a sharp stylus (radius 1-2 nm attached to the cantilever) was used in the AFM to scan point by point while contouring it with a constant small force applied to the stylus.

\section{Results and Discussion}

\subsection{Compositional Studies}

The compositional analysis of the films was carried

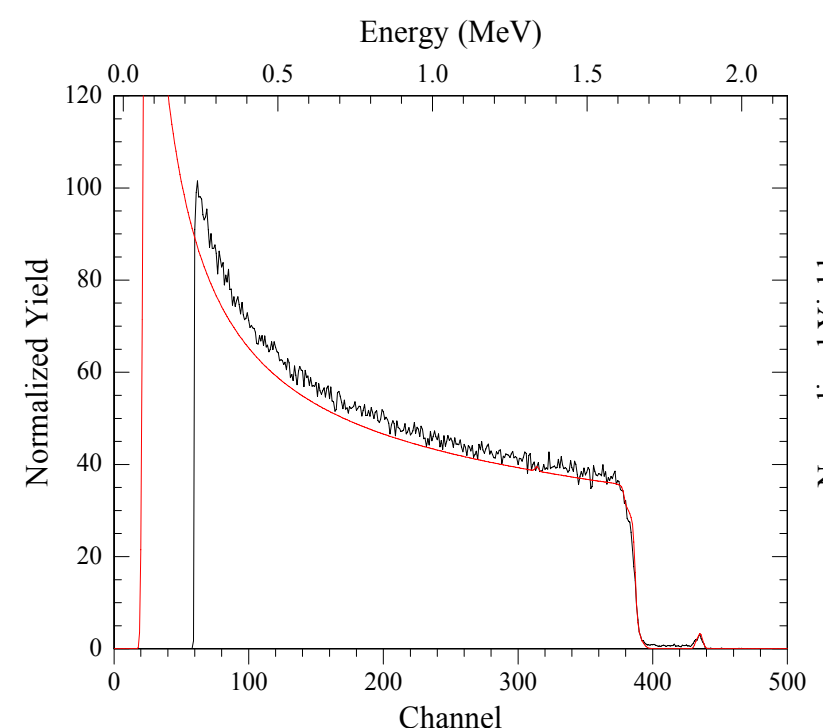

(a)

Energy $(\mathrm{MeV})$

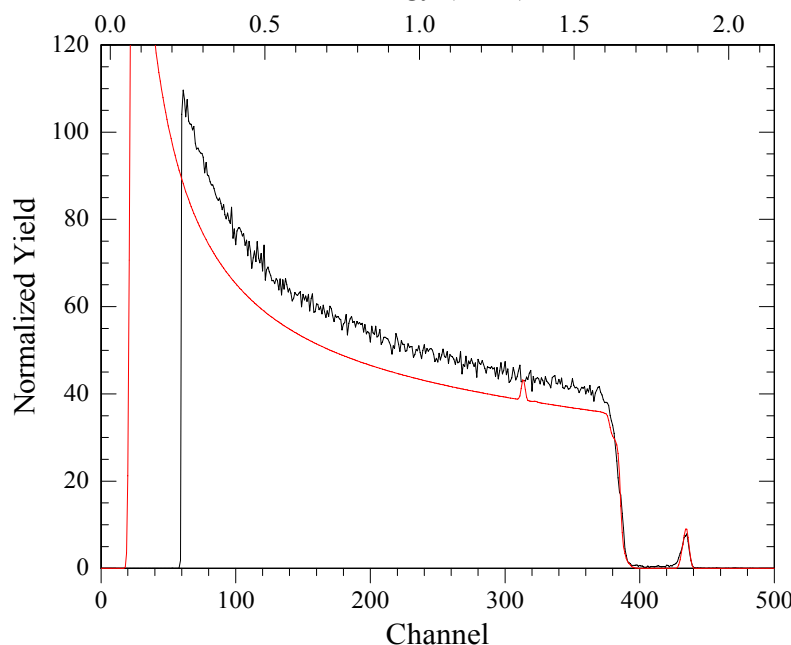

(c) out using Rutherford backscattering spectroscopy (RBS). RBS was also used to determine the thickness of the films. The RBS spectrum of the films deposited on stainless steel at various temperatures are shown in Figs. 1a-1d. From the RBS study, it is evident that the decomposition of bis-(morpholinodithioato-s,s')-Mo in inert gas medium (Argon) produced molybdenum sulphide thin films of various stoichiometry with $\mathrm{S} / \mathrm{Mo}$ ratio ranging from 1.22 to 2.33 while varying the deposition temperature from $360{ }^{\circ} \mathrm{C}$ to $450{ }^{\circ} \mathrm{C}$. This reveals that the stoichiometry of the deposited films can be controlled by deposition temperature. Also, there was no appreciable amount of impurity atoms in

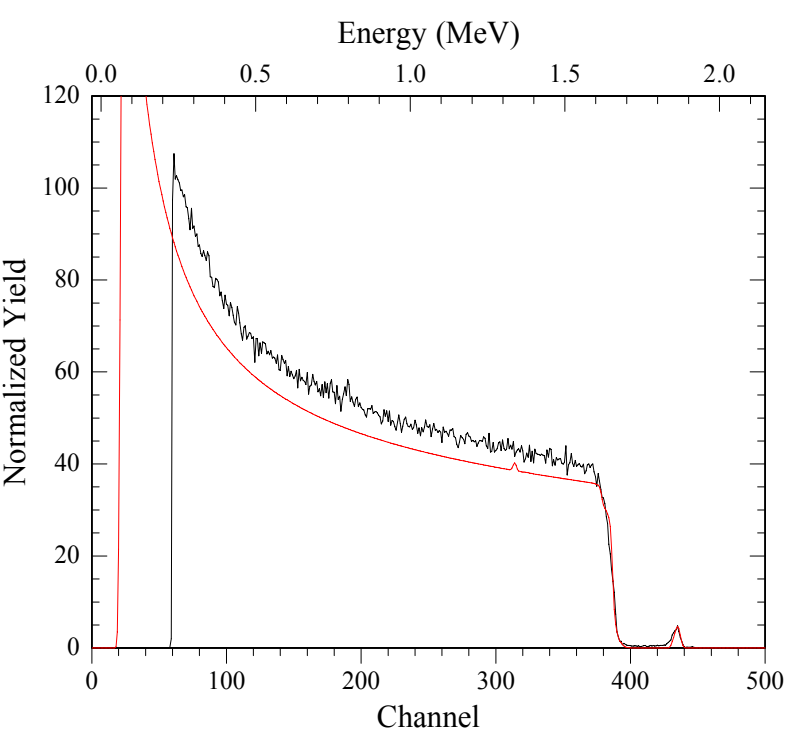

(b)

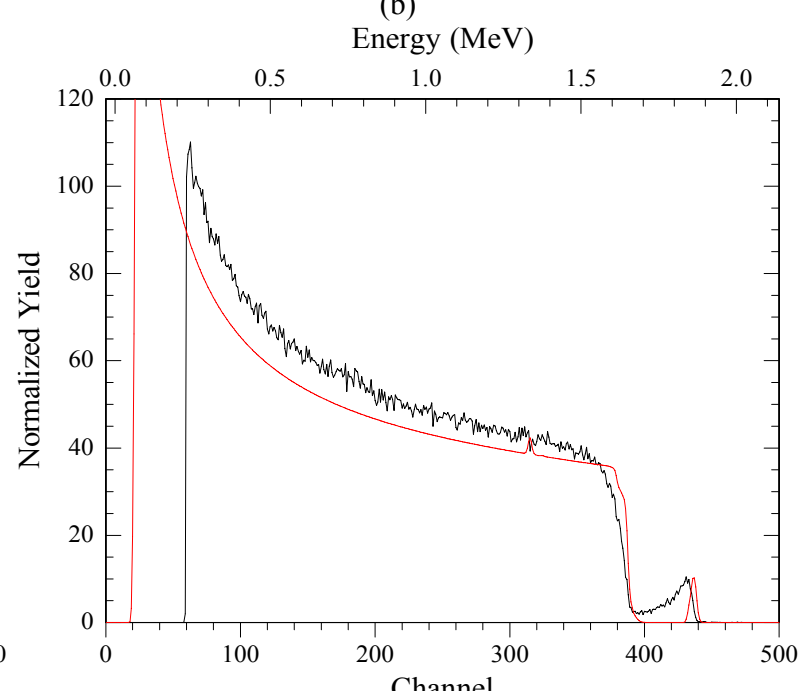

(d)

Fig. 1 RBS spectrum of the thin films: (a) $360{ }^{\circ} \mathrm{C}$, (b) $380{ }^{\circ} \mathrm{C}$, (c) $400{ }^{\circ} \mathrm{C}$ and (d) $450{ }^{\circ} \mathrm{C}$. 
the films. It has also been reported earlier in another paper that the ratio was approximately $2: 1$ at deposition temperature of $420{ }^{\circ} \mathrm{C}$ [15].

The deposition temperature also controls the thickness of the films. The thickness increases gradually from $45 \mathrm{~nm}$ at $360{ }^{\circ} \mathrm{C}$ to $73 \mathrm{~nm}$ at $450{ }^{\circ} \mathrm{C}$. Temperature dependence of thickness can be attributed to the fact that the nucleation rate of the films in the hot zone depend on temperature. Generally, more thermal energy become available as temperature increases, which in turn accelerates the chemical reactions in the reaction chamber. On the other hand, the MOCVD process is also more kinetic dependent than diffusion dependent. As a result, the increase in thickness can also be attributed to the increase of kinetic reaction process in the reaction chamber as the temperature increases.

\subsection{Optical Characterization}

Optical characterization constitutes the most direct and perhaps the simplest approach for probing structure-property relationships in solids. The UV-visible spectra of the thin films at different temperatures on sodalime glass substrate are shown in Fig. 2. Each spectrum is a plot of absorbance against incident photon wavelength at normal incidence and at room temperature. The UV-Visible spectra show that the optical absorbance of the films increase with increasing energy of the photon indicating that the film is highly absorbing in the UV region.

The absorption coefficient $\alpha$ was calculated from the expression:

$$
\alpha=\frac{1}{x} \operatorname{In}\left(\frac{1}{T}\right)
$$

where, $x$ is the thickness of the film, $T=10^{-\mathrm{A}}$ is the transmittance and $A=$ absorbance. The dependence of absorption coefficient on photon energy can be obtained for optical transition processes using the time-dependent perturbation theory. This follows a power law of the general form:

$$
\alpha=A\left(h v-E_{g}\right)^{n}
$$

where $h=$ Planck's constant, $v=$ frequency, $E_{g}=$ energy gap and $A=$ constant of proportionality. The exponent, $n$, characterizes the transition process within the bands and for direct allowed transition it takes a value of $1 / 2$. For direct allowed transition, square of the absorption coefficient $\alpha^{2}$ was calculated. Fig. 3 shows the plot of $\alpha^{2}$ against the energy of the photon for the thin films at temperatures 360 to $450{ }^{\circ} \mathrm{C}$. The extrapolation of the straight region of the graph to the energy axis gives the direct band gap energy for the thin films. The estimated values of the band gaps are $1.69 \mathrm{eV}\left(360^{\circ} \mathrm{C}\right), 1.72 \mathrm{eV}\left(380{ }^{\circ} \mathrm{C}\right), 1.74 \mathrm{eV}\left(400{ }^{\circ} \mathrm{C}\right)$ and $1.79 \mathrm{eV}\left(450^{\circ} \mathrm{C}\right)$. This falls between the values of the band gaps reported for molybdenum sulphide thin films $[1-4,16]$. It is obvious that the band gap depends on the deposition temperature of the thin film.

The increase in the band gap can be explained using different phenomena. It may be as a result of excess sulphur in the film as the deposition temperature increases as shown in the RBS result. Kim and Kim (1996) [17] have interpreted such increase in the band gap of their films by the presence of excess sulphur. It can also be as a result of increase in particle size which can further be explained from three dimensional quantum size effect in which electrons are localized in individual crystallites. Some authors have attributed the broadening of the band gap of $\beta-\operatorname{In}_{2} \mathrm{~S}_{3}$ thin films to the quantum size effect $[18,19]$. Analogous to the present study, the increase in deposition temperature

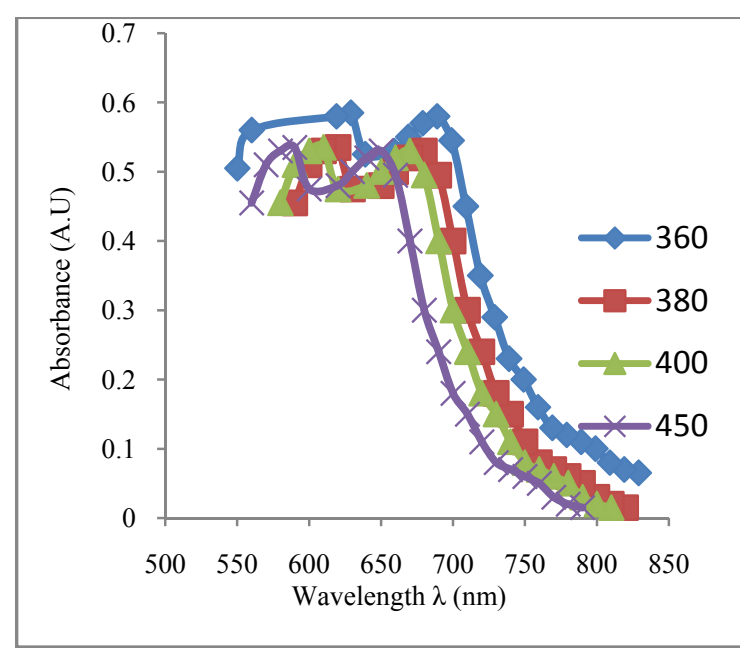

Fig. 2 Absorbance versus wavelength for the thin films. 


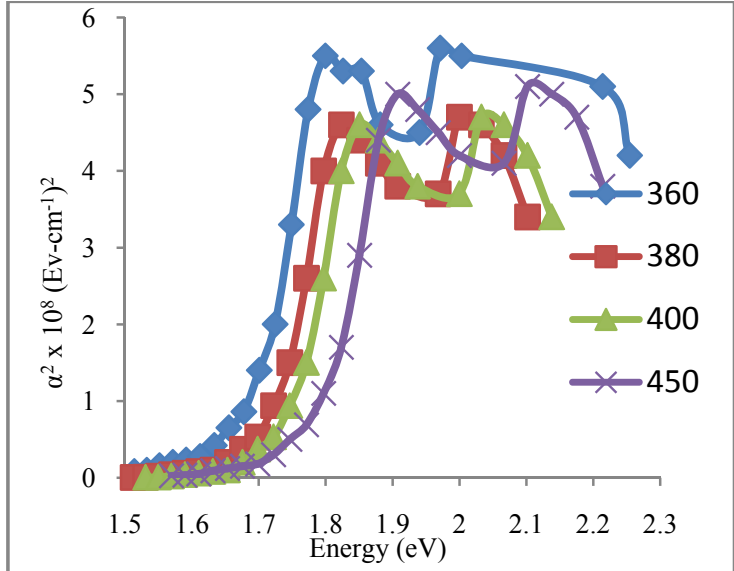

Fig. $3 \alpha^{2}$ versus energy for the thin films.

can cause an increase in the grain size of the films which in turn causes an increase in the band gap. Another possibility for the increase in band gap can be attributed to the partial substitution of oxygen for sulphur to form $\mathrm{MoS}_{2-\mathrm{x}} \mathrm{O}_{\mathrm{x}}$; however no oxides were detected from the RBS.

\subsection{Electrical Characterization}

Electrical characterization of the films was done using the four point probe method. The I-V characteristics of each film were measured two to three times with current and voltage point swapped in each setting in order to minimize error. The average of the current and voltage values were then taken and the sheet resistance Rs of the films was calculated using the expression [20]:

$$
R_{s}=\frac{\pi}{\ln 2}\left(\frac{V}{I}\right)
$$

This was then multiplied with the thickness values from RBS to obtain the resistivity of the films. The conductivity was then obtained by finding the reciprocal of the resistivity. Table 1 summarizes the sheet resistant, resistivity, conductivity and other properties of the films deposited at various temperatures.

The sheet resistance of films at different deposition temperatures is of the order of the same magnitude with those reported in literature $[4,13]$. The conductivity varies from $0.50 \Omega^{-1} \mathrm{~cm}^{-1}$ to $1.30 \Omega^{-1} \mathrm{~cm}^{-1}$ indicating that the conductivity increases with increasing deposition temperature. The values reported in the literature falls within $10^{-3} \Omega^{-1} \mathrm{~cm}^{-1}$ to $10^{1} \Omega^{-1} \mathrm{~cm}^{-1}[12,21,22]$. Very low conductivity values of molybdenum sulphide thin films may be an indication of high impurities like oxygen in the film $[21,22]$. With the range of values obtained in this work for different deposition temperature on the high side, it can then be suggested that our films contain no oxygen as earlier shown in the RBS result.

\subsection{Surface Morphology}

Fig. 4 shows the SEM micrographs of the films (deposited on silicon wafer) at different deposition temperature. The micrographs were analyzed using IMAGEJ software to obtain the grain size. The micrographs confirm the successful manipulation of molybdenum sulphide thin film microstructure by depositing at different temperature. The grain size was found to increase from $1.6 \mu \mathrm{m}$ to $2.4 \mu \mathrm{m}$. This indicates that the average grain sizes of the films are less than 3 $\mu \mathrm{m}$. The increase in grain size may be due to the coalescence of small crystal. A similar temperature-dependent grain sizes were reported by Cheon et al. [12] and Auborn et al. [23] which was attributed to the fact that the rate of deposition increases more quickly than the rate of nucleation.

Table 1 Compositional analysis, thickness, band gap, sheet resistance, resistivity and conductivity of the films deposited at various temperatures.

\begin{tabular}{lllllll}
\hline $\begin{array}{l}\text { Deposition } \\
\text { Temperature }\left({ }^{\circ} \mathrm{C}\right)\end{array}$ & S/Mo ratio & Thickness $(\mathrm{nm})$ & $\begin{array}{l}\text { Band Gap } \\
(\mathrm{eV})\end{array}$ & $\begin{array}{l}\text { Sheet Resistance } \mathrm{x} \\
10^{5}(\Omega / \mathrm{sq})\end{array}$ & Resistivity $(\Omega \mathrm{cm})$ & $\begin{array}{l}\text { Conductivity } \\
\left(\Omega^{-1} \mathrm{~cm}^{-1}\right)\end{array}$ \\
\hline 360 & 1.22 & 45 & 1.69 & 4.48 & 2.02 & 0.50 \\
380 & 1.50 & 50 & 1.72 & 3.44 & 1.72 & 0.58 \\
400 & 1.63 & 70 & 1.74 & 2.55 & 1.79 & 0.56 \\
450 & 2.33 & 73 & 1.79 & 1.78 & 0.77 & 1.30 \\
\hline
\end{tabular}



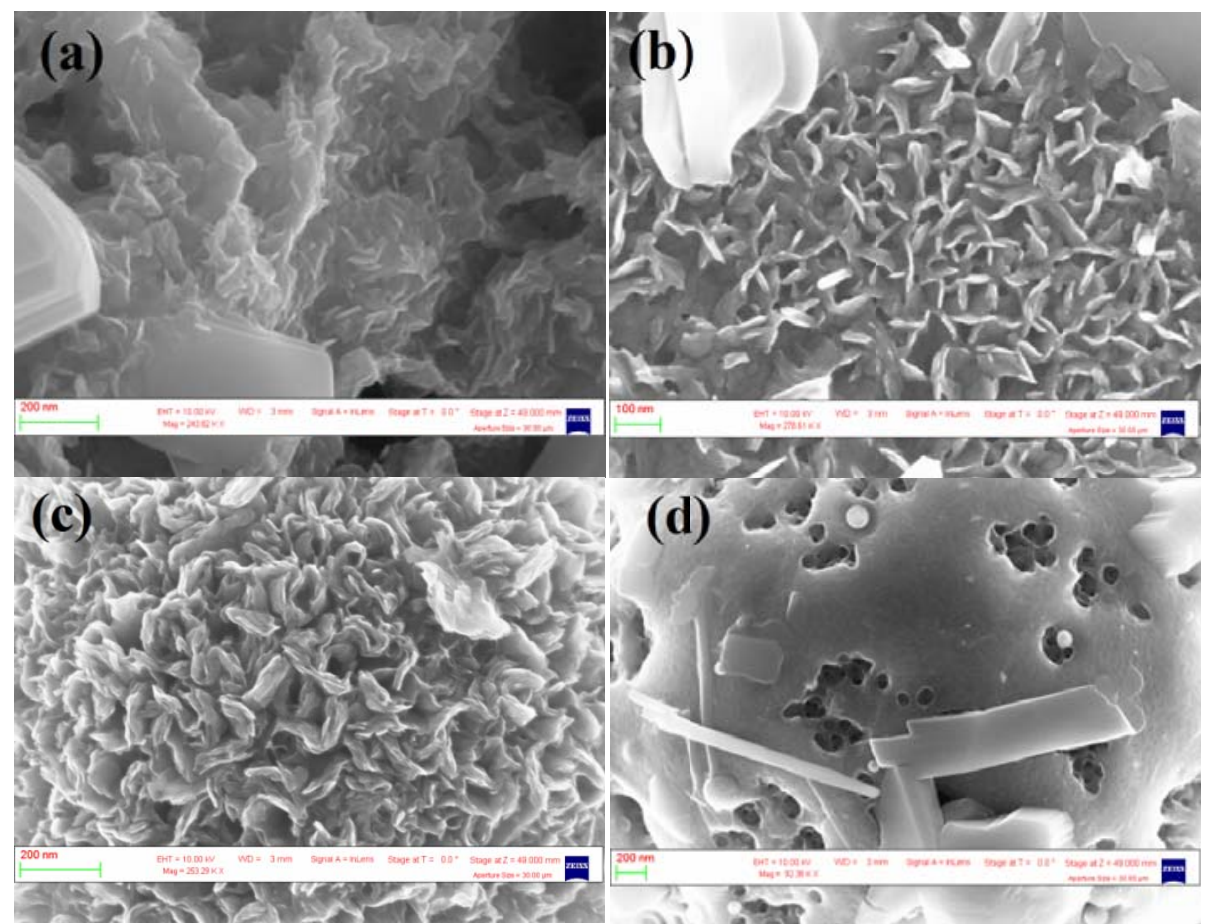

Fig. 4 SEM micrograph of the thin films deposited at: (a) $360{ }^{\circ} \mathrm{C}$, (b) $380{ }^{\circ} \mathrm{C}$, (c) $400{ }^{\circ} \mathrm{C}$ and (d) $450{ }^{\circ} \mathrm{C}$.
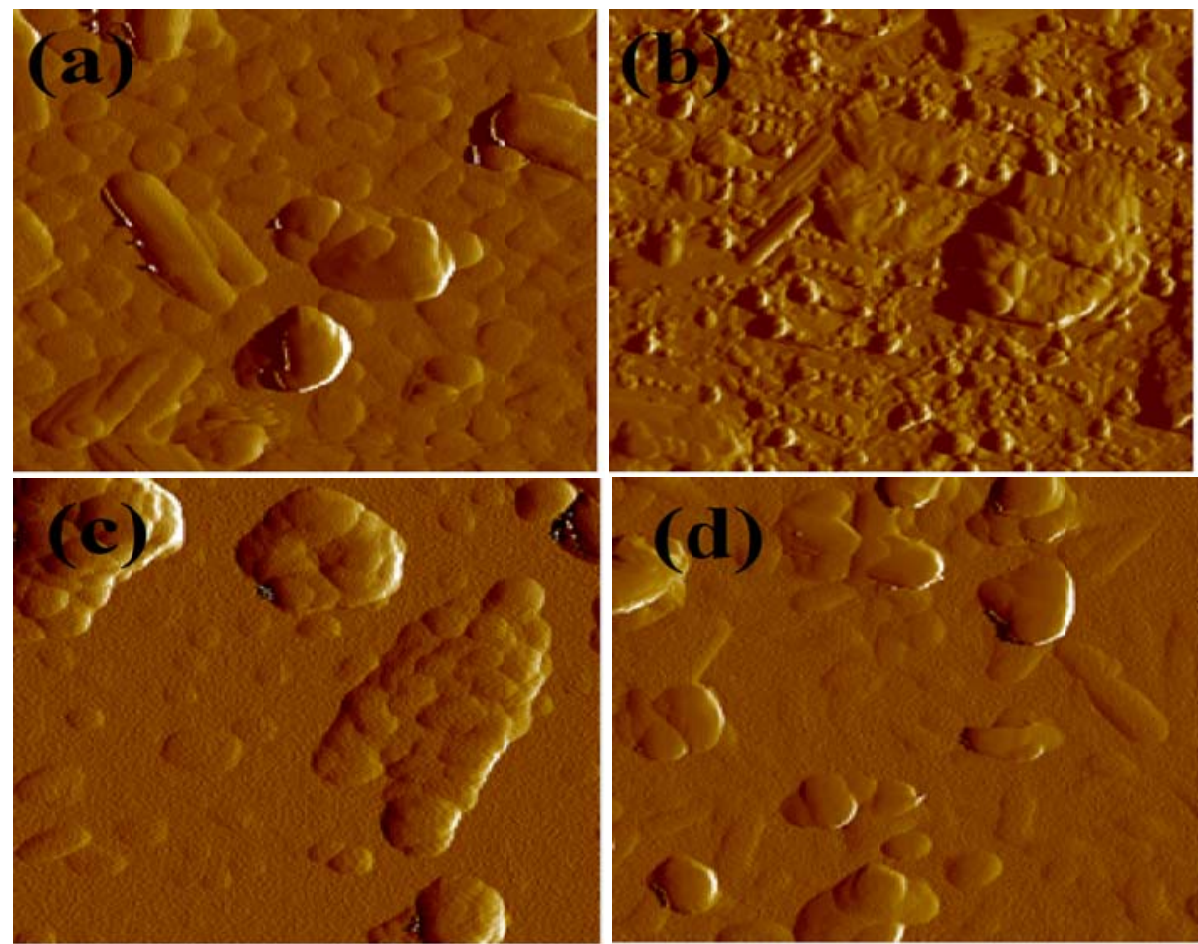

Fig. 5 AFM images of the thin films at: (a) $360^{\circ} \mathrm{C}$, (b) $380{ }^{\circ} \mathrm{C}$, (c) $400{ }^{\circ} \mathrm{C}$ and (d) $450{ }^{\circ} \mathrm{C}$.

The micrograph of the film at $360{ }^{\circ} \mathrm{C}$ clearly shows the layered structure of the film. At $380{ }^{\circ} \mathrm{C}$, the grains begin to cluster together to grow into a definite shape. The layered structure of the film is also seen at $400{ }^{\circ} \mathrm{C}$ growing into a spherical structure. At $450{ }^{\circ} \mathrm{C}$, the grains grow into a more definite structure still showing the layered structure of the film which also appears porous. 
It can then be seen that the surface morphology of the films is very sensitive to deposition temperature. As the temperature increases, the mobility of atoms and their diffusion coefficient become larger. With the atoms having enough diffusion energy, more atoms can then move to the surface and occupy the correct site in the crystal lattice. Thus the grains with energetically favored orientation become larger making the crystallites become more clearly defined with spherical growth features. This behavior probably means that the rate of deposition increases with temperature.

Atomic force microscopy was done in the non-contact mode. The surface roughness of the films over a cross sectional area of $10 \mu \mathrm{m}^{2}$ is as shown (in 2-D) in Figs. 5a-5d. Root mean square surface roughness values for these films is less than $50 \mathrm{~nm}$, indicating that the films are relatively smooth. It was also observed that the deposition temperature has little or no effect on the surface roughness of the films.

\section{Conclusions}

Attempt has been made in this study to deposit molybdenum sulphide thin films at different temperatures from a single solid source precursor using MOCVD technique. The effects of the deposition temperature on stoichiometry and thickness, morphology, as well as the electrical and optical properties of the deposited films were also study. Based on the result obtained in this work, the following conclusion can then be made.

RBS confirmed the expected elements in which the stoichiometry varies with deposition temperature with $\mathrm{S} /$ Mo ratio increasing from 1.22 to 2.33 while varying the deposition temperature from $360^{\circ} \mathrm{C}$ to $450{ }^{\circ} \mathrm{C}$. This show that the stoichiometry depends on deposition temperature.

The thickness of the films as estimated by RBS also depend on the deposition temperature and ranges between $45 \mathrm{~nm}$ to $73 \mathrm{~nm}$ as the deposition temperature increases.

Optical characterization reveal that the films are highly absorbing in the UV part of the spectrum with a direct band gap that varies between $1.69 \mathrm{eV}$ and 1.79 $\mathrm{eV}$ as the deposition temperature increases from $360{ }^{\circ} \mathrm{C}$ to $4,500{ }^{\circ} \mathrm{C}$.

Electrical characterization using four point probe method shows that the resistivity of the films is of the same order of magnitude whereas the conductivity varies from $0.50 \Omega^{-1} \mathrm{~cm}^{-1}$ to $1.30 \Omega^{-1} \mathrm{~cm}^{-1}$ with increasing temperature.

The morphological studies as carried out by SEM and AFM showed that the grain size is less than $3 \mu \mathrm{m}$ and increases from $1.6 \mu \mathrm{m}$ to $2.4 \mu \mathrm{m}$ (as the deposition temperature increases) with roughness value that is less $50 \mathrm{~nm}$ in all the films.

\section{References}

[1] P.K. Nair, J. Campos, M.T.S. Nair, Optoelectronics characteristics of chemically deposited cadmium sulphide thin films, Semicond. Sci. Technol. 3 (2) (1988) 134-145.

[2] E.A. Ponomarev, M. Neumann-Spallart, G. Hodes, C. Lévy-Clement, Electrochemical deposition of $\mathrm{MoS}_{2}$ thin films by reduction of tetrathiomolybdate, Thin Solid Films 280 (1-2) (1996) 86-89.

[3] Jamieson, G. Jakovidis, Thin film texture of layered molybdenum disulphide for photovoltaic cells, Optoelectron. Microelectron. Mater. Dev. 8 (8) (2004) 117-120.

[4] E.A. Ponomarev, R. Tenne, A. Katty, C. Lévy-Clem-ent, High oriented photoactive polycrystalline $\mathrm{MoS}_{2}$ layers obtained by Van der Waals rheotaxy technique from elecrochemically deposited thin films, Sol. Energy Mater. Sol. Cells 52 (1) (1998) 125-133.

[5] Y.B. Li, Y. Bando, D. Goldberg, K. Kurashima, Field emission from $\mathrm{MoO}_{3}$ nanobelts, Appl. Phys. Lett. 81 (26) (2002) 5048-5050.

[6] Y.B. Li, Y. Bando, D. Goldberg, $\mathrm{MoS}_{2}$ nanoflowers and their field emission properties, Appl. Phys. Lett. 82 (12) (2003) 1962-1964.

[7] T. Caillat, J.P. Fleurial, G.J. Synder, Potential of chevrel phases to thermoelectric applications, Solid State Sci. 1 (7-8) (1999) 535-544.

[8] C. Song, An overview of new desulfurization for ultra-clean gasoline, diesel fuel and jet fuel, Catal. Today 86 (1-4) (2003) 211-263.

[9] J. Moser, J. H. Liao, F. Levy, Texture characterization of sputtered $\mathrm{MoS}_{2}$ thin films by cross section TEM analysis, J. Phys. D: Appl. Phys. 23 (5) (1990) 624-626. 
[10] J.K.G. Panitz, L.E. Pope, J.E. Lyons, D.J. Staley, The tribological properties of $\mathrm{MoS}_{2}$ coatings in vacuum low relative humidity and high relative Humidity environments, J. Vac. Sci. Technol. A 6 (3) (1988) 1166-1170.

[11] Endler, A. Leonhardt, U. Kong, H. Van der Berg, W. Pitschke V. Sottke, Chemical vapour deposition of $\mathrm{MoS}_{2}$ coatings using the precursor $\mathrm{MoCl}_{5}$ and $\mathrm{H}_{2} \mathrm{~S}$, Surf. Coat. Technol. 120-121 (1999) 482-488.

[12] J. Cheon, J.E. Gozum, G.S. Girolami, Chemical vapour deposition of $\mathrm{MoS}_{2}$ and $\mathrm{TiS}_{2}$ films from the metal-organic precursors $\mathrm{Mo}(\mathrm{S}-\mathrm{t}-\mathrm{Bu})_{4}$ and $\mathrm{Ti}(\mathrm{S}-\mathrm{t}-\mathrm{Bu})_{4}$, Chem. Mater. 9 (8) (1997) 1847-1853.

[13] D.M. Schleich, H.S. Chang, Y.L. Barberio, K.L. Hanson, $\mathrm{MoS}_{3}$ Thin film cathodes prepared by chemical vapour deposition, J. Electrochem. Soc. 136 (11) (1989) 3274-3278.

[14] H.M. Pathan, C.D. Lokhande, Deposition of metal chalcogenide thin films by successive ionic layer adsorption and reaction (SILAR) method, Bull. Mater. Sci. 27 (2) (2004) 85-111.

[15] B. Olofinjana, G. Egharevba, B. Taleatu, O. Akinwunmi, E.O. Ajayi, MOCVD of molybdenum sulphidethin film via single solid source precursor Bis(Morpholinodithioato-s,s')-Mo, J. Modern Phys. 2 (2011) 341-349.

[16] R.S. Patil, Electrosynthesis of molybdenum disulphide thin films and characterization, Thin Solid Films 340 (1-2), (1999) 11-12.
[17] W.T. Kim, C.D. Kim, Optical energy gaps of $\beta-\operatorname{In}_{2} \mathrm{~S}_{3}$ thin films grown by spray pyrolysis, J. Appl. Phys. 60 (1986) 2631-2634.

[18] K. Yamaguchi, T. Yoshida, H. Minoura, Structural and compositional analysis of indium sulphide thin films deposited in aqueous chemical bath containing indium chloride and thioacetanide, Thin Solid Films 431-432 (2003) 354-358.

[19] R. Yoosuf, M.K. Jayaraj, Optical and photoelectrical properties of $\beta-\operatorname{In}_{2} S_{3}$ thin films prepared by two-stage process, Sol. Energy Sol. Cells 89 (2005) 85-94.

[20] D.K. Schroder, Semiconductor Material and Device Characterizations, Willey-Interscience Publication, Arizona, 1998, pp. 21-25.

[21] Levasseur, E. Schmidt, G. Meunier, D. Gonbeau, L. Benoist, G. Pfister-Guillouzo, New Amorphous molybdenum oxysulphide thin films: their characterization and their electrochemical properties, J. Power Sources 54 (2) (1995) 352-355.

[22] E. Schmidt, C. Sourisseau, G. Meunier, A. Levasseur, Amorphous molybdenum oxysulphide thin films and their physical characterization, Thin Solid Films 260 (1) 1995 21-25.

[23] J.J. Auborn, Y.L. Berberio, K.J. Hanson, D.M. Schlech, M.J. Martin, X-ray photoelectron, emission and absorption studies of the electronic structure of molybdenum and tungsten trisulfides and their intercalates, J. Electrochem. Soc.134 (1987) 580-586. 